УДК 621.311.001.63

\title{
МЕТОДОЛОГИЯ ТЕХНИКО-ЭКОНОМИЧЕСКОГО ОБОСНОВАНИЯ ЭЛЕКТРОСЕТЕВЫХ ОБЪЕКТОВ С УЧЕТОМ ОЦЕНКИ НАДЕЖНОСТИ И СИСТЕМНОЙ ЭФФЕКТИВНОСТИ
}

Андрианова Людмила Прокопьевна

д-р техн. наук, профессор

Павлова Зухра Хасановна

д-р техн. наук, профессор

Рябишина Лилия Амировна

канд. техн. наук, доцент

Хакимьянов Марат Ильгизович

д-р техн. наук, профессор

Хазиева Регина Тагировна

канд. техн. наук, доцент

ФГБОУ ВО Уфимский государственный нефтяной технический

университет

Аннотация. В статье приведена современная методика техникоэкономического обоснования при реконструкции и новом строительстве электросетевых объектов, изложенная в соответствии с требованиями действующих нормативных документов. При обосновании используется формула приведенных (дисконтированных) затрат. Приведены технические требования, учитываемые при обосновании; математические соотношения для определения капитальных вложений по укрупненным стоимостным показателям с учетом затрат на ремонт, обслуживание и на возмещение потерь электроэнергии. Приведена методика оценки экономических последствий отказов элементов сети с учетом показателей надежности авто(трансформаторов) и воздушных линий, а также агрегированных значений удельных ущербов из-за недоотпуска электроэнергии. Приведены способы определения системного эффекта в зависимости от функционального назначения электросетевого объекта.

Ключевые слова: технико-экономическое обоснование, электросетевые объекты, капитальные вложения, укрупненные стоимостные показатели, ежегодные издержки, показатели надежности, системная эффективность. 


\title{
METHODOLOGY OF THE FEASIBILITY STUDY ELECTRIC GRID FACILITIES BASED ON AN ASSESSMENT OF THE RELIABILITY AND SYSTEM EFFICIENCY
}

\author{
Andrianova Lyudmila Prokofievna \\ Pavlova Zuhra Khasanovna \\ Ryabishina Liliya Amirovna \\ Khakimjanov Marat Ilgizovich \\ Khazieva Regina Tagirovna
}

\begin{abstract}
The article presents a modern method of feasibility study for the reconstruction and new construction of power grid facilities, set out in accordance with the requirements of current regulatory documents. When justifying, the formula of reduced (discounted) costs is used. The technical requirements that are taken into account in the justification are given; mathematical relations for determining capital investments based on aggregated cost indicators, taking into account the costs of repairs, maintenance and compensation for electricity losses. A method for assessing the economic consequences of failures of network elements is given, taking into account the reliability indicators of cars(transformers) and overhead lines, as well as aggregate values of specific damages due to under-supply of electricity. Methods for determining the system effect depending on the functional purpose of the power grid object are given.
\end{abstract}

Key words: technical and economic feasibility study, power grid facilities, capital investments, consolidated cost indicators, annual costs, reliability indicators, system efficiency.

Развитие электрической сети осуществляется путем последовательного ее усиления за счет сооружения новых и реконструкции действующих электросетевых объектов и вызвано $[1,9]$ :

- необходимостью присоединения к сети новых генерирующих источников и потребителей;

- изменением характера перетоков в сети вследствие неравномерности изменения спроса и его покрытия по энергоузлам;

- выполнением требований к надежности электроснабжения;

- созданием эффекта от объединения энергосистем при развитии межсистемных связей; 
- повышением экономичности работы энергосистем за счет улучшения режимов работы электростанций и снижения потерь электроэнергии в сетях;

- выполнением обязательств по экспорту мощности и электроэнергии.

Помимо сооружения новых электросетевых объектов производится реконструкция или замена устаревшего оборудования в пределах существующей пропускной способности или с возможным ее увеличением.

Обоснование электросетевых объектов базируется на выполнении следующих технических требований $[1,6,9]$ :

- схема электрической сети должна обладать достаточной гибкостью, позволяющей осуществлять ее поэтапное развитие и иметь возможность приспосабливаться к изменениям внешних условий - росту нагрузки и развитию электростанций, перемене направлений и значений перетоков мощности и др.;

- развитие электрической сети осуществляется для достижения наилучших экономических показателей энергосистем в целом, причем независимо от форм собственности тех или иных объектов электроэнергетики;

- электрическая сеть должна обеспечивать выдачу мощности электростанций, транспорт электроэнергии и электроснабжение потребителей как в нормальном режиме работы сети, не допуская каскадного развития аварий с массовым нарушением снабжения потребителей при аварийных возмущениях;

- увеличение пропускной способности сети в процессе ее развития осуществляется в первую очередь за счет проведения реконструкций существующих линий и применением современных средств компенсации реактивной мощности, а затем - постепенной «надстройкой» линиями более высокой ступени напряжения после достаточно полного охвата территории сетями предыдущего класса напряжения и исчерпания их технических возможностей;

- схема и параметры электрической сети должны обеспечивать требуемую надежность электроснабжения и транзит мощности как в нормальной схеме, так и в ремонтных или послеаварийных режимах при нормативных возмущениях с учетом имеющихся резервов генерирующей мощности, пропускной способности сети, а также допустимой перегрузочной способности оборудования согласно $[1,2]$;

- развитие электрической сети должно соответствовать требованиям охраны окружающей среды.

Для обоснования электросетевых объектов $[1,2,9]$ : 
- формируются балансы мощности и электроэнергии в регионе на базе прогнозных нагрузок на заданную перспективу;

- проводятся расчеты электрических режимов для нормальных, ремонтных и послеаварийных схем в режимах максимума и минимума нагрузки зимнего рабочего дня, а также максимума нагрузки летнего рабочего дня и минимума нагрузки летнего выходного дня. При необходимости рассматривается режим паводка.

При обосновании электросетевых объектов во внимание принимаются схемы и параметры оборудования, установленного на электростанциях и подстанциях рассматриваемого региона:

- главные схемы электрических соединений электростанций и подстанций;

- номинальные параметры коммутационного оборудования с указанием типов выключателей и полного времени их отключения, трансформаторов тока и высокочастотных заградителей;

- параметры срабатывания устройств релейной защиты и автоматики (РЗА), а именно основных и резервных защит, устройств резервирования отказов выключателя (УРОВ) и автоматического повторного включения (АПВ), а также противоаварийной автоматики (ПА);

- длительно допустимые и аварийно допустимые токовые нагрузки проводов, кабелей ЛЭП, ошиновок ПС и силовых (авто)трансформаторов.

- стоимость потерь электроэнергии.

При технико-экономическом обосновании электросетевых объектов используется формула приведенных (дисконтированных) затрат, как сумма капиталовложений $K$ и издержек $И$ в общем случае за некоторый расчетный период времени $T_{\text {расч }}$

$$
\overline{3}_{i}=\sum_{t=1}^{T_{\text {расч }}}\left(K_{t}+H_{t}\right)\left(1+E_{\mathrm{H. \Pi}}\right)^{i-t},
$$

где $K_{t}$ и $h_{t}-$ капиталовложения и издержки в $t$-й год;

$E_{\mathrm{H.II}}-$ норматив приведения разновременных затрат (ставка дисконтирования).

Если строительство объекта осуществляется за год, год приведения затрат $i=1$ и $t \leq T_{\text {расч }}$, а со второго года наступает период его эксплуатации, то, выражение (1) преобразуется к виду (2) 


$$
\overline{3}_{i}=K+H \sum_{t=2}^{T}\left(1+E_{\mathrm{H. \Pi}}\right)^{1-t} .
$$

При $n=T_{\text {расч}}$, вместо (2) может быть использована более простая форма

$$
\overline{3}_{i}=K+И\left[\frac{\left(1+E_{\mathrm{H} . \mathrm{I}}\right)^{n}-1}{E_{\mathrm{H} . \mathrm{I}}\left(1+E_{\mathrm{H} . \mathrm{I}}\right)^{n}}\right] .
$$

Альтернативные варианты при обосновании электросетевых объектов сравниваются по значению дисконтированных затрат за расчетный период времени. Выбор предпочтительного варианта ведется по их минимуму. За расчетный период времени рекомендуется принимать минимальный расчетный срок службы 30 лет, соответствующей минимальному расчетному сроку службы основного оборудования подстанции - силовых (авто)трансформаторов, оборудования открытого распределительного устройства (ОРУ) 110 кВ и выше [3].

Ставка дисконтирования принимается на уровне нормы доходности инвестированного капитала для расчета тарифов на услуги по передаче электроэнергии в единой национальной электрической сети (ЕНЭС), без учета инфляции. Размер инфляции определен в соответствии с базовым вариантом прогноза социально-экономического развития на среднесрочный период, одобренным Правительством Российской Федерации.

Капитальные вложения в формулах (1) - (3) определяются по укрупненным стоимостным показателям [4], которые приведены в базисном уровне цен по состоянию на 01.01.2000 г. и без НДС.

Ежегодные издержки для электросетевых объектов определяют как

$$
K=U_{\text {рем }}+h_{\text {обсл }}+h_{\Pi}+y_{0} \Delta W,
$$

где $И_{\text {рем }}$ - затраты на ремонты электроустановок;

$И_{\text {обсл }}$ - затраты на обслуживание электроустановок;

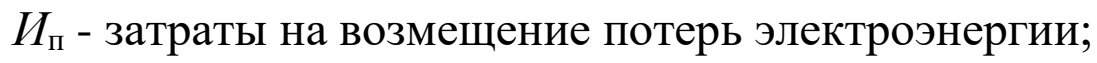

$y_{0} \Delta W$ - затраты, связанные с экономическими последствиями из-за отказов электроустановок;

$y_{0}$ - обобщенный (агрегированный) удельный ущерб;

$\Delta W$ - математическое ожидание недоотпуска электроэнергии.

Состав условно постоянных ежегодных затрат на производство электроэнергии объектами генерации включает затраты на ремонт и обслуживание электроустановок

$$
И=h_{\text {рем }}+H_{\text {обсл}} \text {. }
$$


Стоимость условно переменной составляющей затрат (топливной составляющей) исключена из (5), так как в альтернативных вариантах электроустановки баланс электроэнергии в энергосистеме считается практически неизменным с позиций конечных потребителей.

Удельные показатели капитальных вложений переводятся в текущие и прогнозные цены с применением ретроспективных индексов-дефляторов инвестиций в основной капитал, указанных в базовом варианте прогноза социально-экономического развития на среднесрочный период Министерства экономического развития РФ. В СТО [9] указано, что по реальным проектам удельные капитальные вложения на современные парогазовые установки составляют в ценах 2000 г. примерно 11,6...13,3 тыс. руб./кВт, а на угольные электростанции - 16,1..17,9 тыс. руб./кВт без учета затрат на схему выдачи мощности. К полученным значениям удельных капиталовложений вводится повышающий коэффициент $1,1 \ldots 1,2$, учитывающий необходимость создания всех видов резервов генерирующей мощности в энергосистемах.

Стоимость отчуждаемых земельных участков для подстанций и воздушных линий определяется с учетом размеров необходимых постоянных отводов земель согласно правилам определения размеров земельных участков для размещения воздушных линий электропередачи и опор линий связи, обслуживающих электрические сети, утвержденных Постановлением Правительства РФ от 11.08.2003 № 486 «Об утверждении Правил определения размеров земельных участков для размещения воздушных линий электропередачи и опор линий связи, обслуживающих электрические сети» и нормам отвода земель для электрических сетей напряжением 0,38-750 кВ, утвержденных приказом Минтопэнерго России от 20.05.1994 № 14278тм-т1.

Ежегодные издержки на ремонты и обслуживание элементов электрической сети определяются в виде отчислений от соответствующих капитальных вложений. Ориентировочные значения отчислений приведены в [6]. Ежегодные затраты на ремонты и обслуживание объектов генерации регламентируются Постановлением Правительства РФ от 13.04.2010 № 238 в ценах на 01.01.2010.

Стоимость нагрузочных потерь электроэнергии в линиях электропередачи

$$
h_{\Pi}=c_{\ni} \Delta P_{\max } \tau_{\max }
$$

где $c_{\ni}$ - удельная стоимость потерь электроэнергии;

$\Delta P_{\max }-$ потери активной мощности в режиме наибольшей нагрузки; 
$\tau_{\max }-$ годовое время максимальных потерь.

Значения $\tau_{\max }$ в зависимости от числа часов использования максимума нагрузки $T_{\max }$ приведены в таблице 1 .

Таблица 1

Зависимость годового времени максимальных потерь от числа часов использования максимума нагрузки [C]

\begin{tabular}{|l|l|l|l|l|l|l|l|l|}
\hline$T_{\max }$, ч & 2500 & 3000 & 4000 & 5000 & 6000 & 7000 & 8000 & 8760 \\
\hline$\tau_{\max }$, ч & 1000 & 1250 & 1800 & 2750 & 3800 & 5500 & 7350 & 8760 \\
\hline
\end{tabular}

Значения $T_{\max }$ при отсутствии более точных данных могут быть приняты в диапазоне от 6000 до 7600 ч для четырех условных групп [9, с.10]:

- Сибирские регионы с $T_{\max }=7500-7600$ ч с промышленным характером нагрузки, показательным для районов нефтедобычи, усиливаемым в ряде случаев высокой долей гидроэлектростанций в структуре генерирующих мощностей;

- Уральские регионы с $T_{\max }=6700-6800$ ч с характером нагрузки, наблюдаемым в зоне крупных промышленных центров и городов;

- Центральные регионы с $T_{\max }=6400-6500$ ч со смешанным характером нагрузки и заметной долей электропотребления в быту и сфере услуг;

- Южные регионы с $T_{\max }=6100-6200$ ч со смешанным характером нагрузки, заметной долей электропотребления в быту и сфере услуг, а также развитым сельскохозяйственным производством.

Стоимость потерь электроэнергии в трехобмоточном (авто)трансформаторе приближенно определяют по формуле

$$
h_{\Pi} \approx c_{\ni}\left(\Delta P_{\mathrm{x}} 8760+\Delta P_{\mathrm{K} \mathrm{B-C}}\left(S_{\max } / S_{\text {ном }}\right)^{2} \tau_{\max }\right),
$$

где $\Delta P_{\mathrm{x}}$ - потери холостого хода;

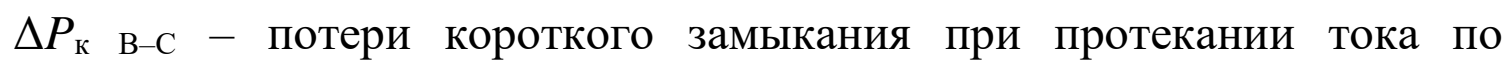
обмоткам высшего и среднего напряжения при разомкнутой обмотке низшего напряжения;

$S_{\max }$ - переток мощности через (авто)трансформатор в режиме наибольших нагрузок в нормальном режиме;

$S_{\text {ном }}$ - номинальная мощность (авто)трансформатора.

Потери мощности на корону в воздушных линиях (ВЛ) определяют по [7], исходя из удельных годовых потерь активной мощности на корону в 
зависимости от номинального напряжения, сечения проводов и района сооружения линии.

Стоимость потерь электроэнергии определяют с учетом ставок тарифа на услуги по передаче электроэнергии, фактического отпуска ее и мощности в течение расчетного периода, а также норматива потерь электроэнергии (приказ Федеральной службы по тарифам от 09.12.2014 № 297-э/3).

Значения стоимости потерь электроэнергии на уровне ЕНЭС при отсутствии более точных данных могут быть приняты по текущим отчетным данным, приведенным к ценам 2000 г. без НДС, на уровне 0,28...0,32 руб./(кВт·ч), за исключением Северо-Кавказского федерального округа с 0,41 руб./(кВт·ч).

При определении экономических последствий отказов $\left(y_{0} \Delta W\right)$ результирующее математическое ожидание недоотпуска электроэнергии в энергосистеме в $i$-х расчетных режимах определяют по соотношению

$$
\sum_{i} \Delta W_{i}=\sum_{i} \Delta P_{i} K_{\text {прi }} T_{\max }
$$

где $\Delta P_{i}-$ ограничение мощности;

$K_{\text {прі }}$ - коэффициент вынужденного простоя схемы.

Во внимание принимаются события, связанные с совпадением аварийного отключения одного элемента электрической сети с плановым ремонтом другого элемента. Оцениваются экономические последствия таких отказов и их влияние на надежность электроснабжения.

Частота отказов, 1/год, событий определяется по соотношению:

$$
\begin{gathered}
\omega_{\Sigma}=\omega^{0}+\omega^{\prime}+\omega^{\prime \prime}=\omega_{1} \omega_{2}\left(T_{\text {в } 1}+T_{\text {в } 2}\right) / 8760+\omega_{1} \mu_{2} T_{\text {пл } 2} / 8760+\omega_{2} \mu_{1} T_{\text {пл1 }} / 8760 \approx \\
\approx \omega_{1} \mu_{2} T_{\text {пл2 } 2} / 8760+\omega_{2} \mu_{1} T_{\text {пл1 } 1} / 8760,
\end{gathered}
$$

где $\Phi^{0}-$ частота отказов первого элемента во время аварийного простоя второго; $\varpi^{\prime}$ и $\varpi^{\prime \prime}$ - то же, но при отказе первого элемента во время планового простоя второго и наоборот соответственно; (средний параметр потока отказов или частота отказов; здесь и далее - индекс «1»- принадлежность условно к первому элементу, индекс «2»- ко второму); $T$ в - среднее время восстановления; $\mu$ - средняя частота плановых ремонтов;

$T_{\text {пл }}$ - средняя продолжительность планового ремонта [8].

Среднее время восстановления схемы определяют по формуле

$$
\begin{aligned}
& T_{\text {в.ср }}=\left(\omega^{0} \tau^{0}+\omega^{\prime} \tau^{\prime}+\omega^{\prime \prime} \tau^{\prime \prime}\right) / \omega_{\Sigma}=\left(\omega^{0} T_{\text {в } 1} T_{\text {в } 2} /\left(T_{\text {в } 1}+T_{\text {в } 2}\right)+\omega^{\prime} T_{\text {в } 1} T_{\text {пл } 2} /\left(T_{\text {в } 1}+T_{\text {пл2 }}\right)+\right.
\end{aligned}
$$

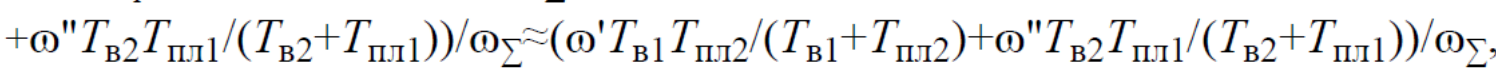


где $\tau^{0}$ - время восстановления схемы при отказе первого элемента схемы во время аварийного простоя второго; $\tau^{\prime}$ и $\tau^{\prime \prime}$ - то же, но при отказе первого элемента во время планового простоя второго и наоборот соответственно.

Как правило, частота $\omega^{0}$ на два - три порядка меньше $\omega^{\prime}$ и $\emptyset^{\prime \prime}$ и поэтому при практических расчетах не учитывается [9, с.12].

Среднее время, ч, работоспособного состояния схемы определяют как

$$
T_{\text {paб }}=8760 / \Phi_{\Sigma} .
$$

Коэффициент вынужденного простоя схемы определяют по формуле

$$
K_{\text {пр }}=T_{\text {в.ср }} /\left(T_{\text {раб }}+T_{\text {в.ср }}\right) \text {. }
$$

Показатели надежности (авто)трансформаторов и воздушных линий, учитываемые при оценке параметров отказов, приведены в таблицах 2 и 3 [1].

Характеристики надежности коммутационных аппаратов при техникоэкономическом обосновании электросетевых объектов допустимо не принимать во внимание, поскольку их влияние на экономические последствия из-за их отказов значительно меньше, чем у ВЛ и (авто)трансформаторов .

Таблица 2

\begin{tabular}{|c|c|c|c|c|c|}
\hline $\begin{array}{l}\text { Напряжение, } \\
\text { кВ }\end{array}$ & 110 & 220 & 330 & 500 & 750 \\
\hline Ф, 1/год & 0,015 & 0,03 & 0,04 & $0,024 / 0,053^{*}$ & $0,024 / 0,053^{*}$ \\
\hline$T 6,4$ & 95 & 60 & 45 & 220 & 220 \\
\hline$\mu, 1 /$ год & $2,1 * *$ & 2,33 & 2,44 & 2,47 & 2,94 \\
\hline Тпл, $ч$ & $134 * *$ & 153 & 169 & 182 & 229 \\
\hline
\end{tabular}

Показатели надежности (авто)трансформаторов [9, с.13]

Таблица 3

\begin{tabular}{|c|c|c|c|c|c|}
\hline $\begin{array}{l}\text { Напряжение, } \\
\text { кВ }\end{array}$ & 110 & 220 & 330 & 500 & 750 \\
\hline $\begin{array}{l}Ф, \\
1 /(\text { год·100 км })\end{array}$ & 0,81 & 0,42 & 0,33 & 0,31 & 0,2 \\
\hline$T 6,4$ & 9,4 & 12,7 & 13,2 & 14,1 & 14,1 \\
\hline$\mu, 1 /$ год & $2,3 * * *$ & 2,6 & 3,1 & 3,2 & 3,0 \\
\hline$T_{n л}, y$ & $85 * * *$ & 98 & 149 & 127 & 159 \\
\hline
\end{tabular}

Показатели надежности воздушных линий $[9$, с.13] 
Экономические последствия из-за недоотпуска электроэнергии в энергосистеме оцениваются по агрегированным (укрупненным) значениям удельных ущербов (Таблица 4).

Таблица 4

Агрегированные значения удельных ущербов[9, с.15]

\begin{tabular}{|l|c|}
\hline Решаемая задача & Удельный ущерб, руб./(кВт·ч) \\
\hline Оценка надежности магистральных сетей & $42 / 244$ \\
\hline Оценка последствий системных аварий & $30 / 175$ \\
\hline $\begin{array}{l}\text { Оценка надежности распределительных } \\
\text { сетей }\end{array}$ & $17 / 99$ \\
\hline Примечание: Числитель - в ценах 2000 г., знаменатель - в ценах 2018 г. \\
\hline
\end{tabular}

При технико-экономической оценке системного эффекта от сооружения электросетевого объекта учету подлежат все дополнительные затраты и выгоды по сравнению с альтернативным вариантом. Функциональное назначение электросетевого объекта определяет такие составляющие системного эффекта:

1) Повышение надежности электроснабжения потребителей;

2) Передача избыточной электроэнергии в дефицитные регионы;

3) Снижение затрат на производство и передачу электроэнергии в энергосистеме за счет оптимизации режимов работы электростанций и снижения потерь мощности и электроэнергии в сети.

В первом случае проявляется системный эффект, заключающийся в снижении экономических последствий из-за ограничения их электроснабжения с позиций ущерба, наносимого обществу, за счет сокращения объема аварийных отключений потребителей.

Во втором случае проявляется системный эффект, заключающийся в снижении затрат на генерирующие источники за счет роста объема передаваемой электроэнергии из избыточных регионов в дефицитные с помощью альтернативных вариантов создания дополнительных генерирующих источников. В случае, если нормативными документами разрешается ограничение нагрузки потребителей, то проявляется системный эффект, заключающийся в снижении экономических последствий из-за ограничения электроснабжения.

В третьем случае проявляется системный эффект, заключающийся в устранении ограничений (разрывов мощности), препятствующих наиболее экономичной работе генераторов электростанций, снижении потерь мощности 
и электроэнергии в электрических сетях, а также сокращении необходимой резервной генерирующей мощности в энергосистеме, за счет того, что суммарный объем поставок через электрическую сеть не меняется.

Способы определения системного эффекта в зависимости от функционального назначения электросетевого объекта приведены в таблицах 5 и 6.

Таблица 5

Способы оценки системного эффекта $[9$, с.16]

\begin{tabular}{|c|c|c|c|c|}
\hline \multirow{2}{*}{$\begin{array}{c}\text { Назначение } \\
\text { объекта }\end{array}$} & \multicolumn{2}{|c|}{ Мощностной эффект } & \multicolumn{2}{|c|}{ Топливный эффект } \\
\hline & $\begin{array}{c}\text { Способ } \\
\text { определения }\end{array}$ & $\begin{array}{c}\text { Экономическая } \\
\text { оценка }\end{array}$ & $\begin{array}{c}\text { Способ } \\
\text { определения }\end{array}$ & $\begin{array}{c}\text { Экономическая } \\
\text { оценка }\end{array}$ \\
\hline $\begin{array}{l}\text { Выдача мощности } \\
\text { электростанций и } \\
\text { от избыточных } \\
\text { регионов }\end{array}$ & $\begin{array}{l}\text { Дополнительные } \\
\text { поставки } \\
\text { мощности на } \\
\text { оптовый рынок }\end{array}$ & $\begin{array}{l}\text { Стоимость } \\
\text { замыкающей } \\
\text { электростанции }\end{array}$ & $\begin{array}{l}\text { Поставки } \\
\text { электроэнергии } \\
\text { на оптовый } \\
\text { рынок. } \\
\text { Улучшение } \\
\text { режима работы } \\
\text { электростанций }\end{array}$ & $\begin{array}{l}\text { Разница в } \\
\text { стоимости } \\
\text { выработки } \\
\text { поставляемой } \\
\text { электроэнергии } \\
\text { по сравнению с } \\
\text { выработкой } \\
\text { вытесняемых } \\
\text { электростанций } \\
\text { оптового рынка }\end{array}$ \\
\hline $\begin{array}{l}\text { Поставки } \\
\text { мощности и } \\
\text { электроэнергии } \\
\text { дефицитным } \\
\text { регионам }\end{array}$ & $\begin{array}{l}\text { Дополнительные } \\
\text { поставки } \\
\text { мощности } \\
\text { дефицитным } \\
\text { регионам }\end{array}$ & То же & $\begin{array}{l}\text { Улучшение } \\
\text { режима работы } \\
\text { электростанций } \\
\text { за счет загрузки } \\
\text { наиболее } \\
\text { экономичных } \\
\text { агрегатов }\end{array}$ & $\begin{array}{l}\text { Разница в } \\
\text { стоимости } \\
\text { выработки } \\
\text { электроэнергии } \\
\text { по сравнению с } \\
\text { выработкой } \\
\text { вытесняемых } \\
\text { электростанций }\end{array}$ \\
\hline $\begin{array}{l}\text { Повышение } \\
\text { надежности } \\
\text { электроснабжения } \\
\text { потребителей }\end{array}$ & $\begin{array}{l}\text { Определение } \\
\text { ограничений } \\
\text { нагрузки } \\
\text { потребителей }\end{array}$ & - & $\begin{array}{l}\text { Определение } \\
\text { математического } \\
\text { ожидания } \\
\text { недоотпуска } \\
\text { электроэнергии } \\
\text { потребителям }\end{array}$ & $\begin{array}{l}\text { По удельной } \\
\text { стоимости } \\
\text { ущербов }\end{array}$ \\
\hline $\begin{array}{l}\text { Межсистемные } \\
\text { связи }\end{array}$ & $\begin{array}{l}\text { Снижение } \\
\text { резервов } \\
\text { генерирующей } \\
\text { мощности }\end{array}$ & $\begin{array}{l}\text { Стоимость } \\
\text { замыкающей } \\
\text { электростанции }\end{array}$ & $\begin{array}{l}\text { Улучшение } \\
\text { режима работы } \\
\text { электростанций }\end{array}$ & $\begin{array}{l}\text { Разница в } \\
\text { стоимости } \\
\text { выработки } \\
\text { электроэнергии } \\
\text { по сравнению с }\end{array}$ \\
\hline
\end{tabular}




\begin{tabular}{|l|l|l|l|l|}
\hline & & & & $\begin{array}{l}\text { выработкой } \\
\text { вытесняемых } \\
\text { электростанций }\end{array}$ \\
\hline
\end{tabular}

\section{Таблица 6}

\section{Интегральный эффект по инвестиционной программе [9, с.16]}

\begin{tabular}{|c|c|c|}
\hline $\begin{array}{l}\text { Группа электросетевых } \\
\text { объектов по функциональной } \\
\text { нагрузке }\end{array}$ & $\begin{array}{c}\text { Физический объем экономии, МВт, } \\
\text { кВт•ч }\end{array}$ & $\begin{array}{c}\text { Экономия затрат, } \\
\text { млн. руб. }\end{array}$ \\
\hline $\begin{array}{l}\text { Выдача мощности от } \\
\text { электростанций и от } \\
\text { избыточных регионов }\end{array}$ & $\begin{array}{l}\text { Отказ от сооружения генерирующих } \\
\text { мощностей дефицитных регионах }\end{array}$ & \multirow{4}{*}{$\begin{array}{l}\text { Разница в затратах } \\
\text { по сетевому и } \\
\text { альтернативному } \\
\text { варианту }\end{array}$} \\
\hline $\begin{array}{l}\text { Поставки мощности и } \\
\text { электроэнергии дефицитным } \\
\text { регионам }\end{array}$ & $\begin{array}{l}\text { Отказ от сооружения генерирующих } \\
\text { мощностей в дефицитных регионах, } \\
\text { экономия топлива }\end{array}$ & \\
\hline $\begin{array}{l}\text { Повышение надежности } \\
\text { электроснабжения } \\
\text { потребителей }\end{array}$ & $\begin{array}{l}\text { Математическое ожидание } \\
\text { недоотпуска электроэнергии } \\
\text { потребителям }\end{array}$ & \\
\hline $\begin{array}{l}\text { Межсистемные связи между } \\
\text { объединенными } \\
\text { энергосистемами }\end{array}$ & $\begin{array}{l}\text { Отказ от сооружения генерирующих } \\
\text { мощностей в дефицитных регионах, } \\
\text { экономия топлива, затрат на } \\
\text { компенсацию потерь электроэнергии }\end{array}$ & \\
\hline
\end{tabular}

Заключение. Представленная методология технико-экономического обоснования электросетевых объектов, построенная с учетом оценок надежности и общественной (системной) эффективности может быть использована при проектировании вновь сооружаемых и реконструируемых электроустановок специалистами и обучающимися в данной предметной области.

\section{Список литературы}

1. Методические рекомендации по проектированию развития энергосистем / CO 153-34.20.118-2003 // www.cius-ees.ru. - Дата обращения 06.12.2020.

2. Об утверждении требований к обеспечению надежности электроэнергетических систем, надежности и безопасности объектов электроэнергетики и энергопринимающих установок «Методические указания 
по устойчивости энергосистем» / Приказ Минэнерго России от 03.08.2018 № 630 // http://publicationpravo.gov.ru. - Дата обращения 06.12.2020.

3. Типовые технические требования к трансформаторам, автотрансформаторам (распределительным, силовым) классов напряжения 110 750 кВ / СТО 56947007-29.180.091-2011 // www.fsk-ees.ru. - Дата обращения 06.12.2020.

4. Укрупнённые стоимостные показатели линий электропередачи и подстанций напряжением 35-1150 кВ» 324 тм - т1 для электросетевых объектов / CTO 56947007-29.240.124-2012 // www.fsk-ees.ru. - Дата обращения 06.12.2020.

5. Об утверждении укрупненных нормативов цены типовых технологических решений капитального строительства объектов электроэнергетики в части объектов электросетевого хозяйства / Приказ Минэнерго России от 17.01.2019 № 10 // http://publication.pravo.gov.ru. - Дата обращения 06.12.2020.

6. Справочник по проектированию электрических сетей / Под ред. Д.Л. Файбисовича // Москва: Изд-во НЦ ЭНАС. - 2012. - 376 с.

7. Об организации в Министерстве энергетики Российской Федерации работы по утверждению нормативов технологических потерь электроэнергии при ее передаче по электрическим сетям / Приказ Минэнерго России от 30.12.2008 № 326 // www.ges-nv.ru . - Дата обращения 06.12.2020.

8. Надежность систем энергетики и их оборудования /Под общей ред. Ю.Н. Руденко: в 4-х т. Т.2: Надежность электроэнергетических систем; под ред. Ю.Н. Розанова // - Москва: Энергоатомиздат, 2000. - 563 с.

9. Методические указания по технико-экономическому обоснованию электросетевых объектов. Эталоны обоснований / СТО 56947007 29.240.01.271-2019: введ. 24.07.2019 // ПАО «ФСК ЕЭС», 2019. - 33 с.

(C) Андрианова Л.П., Павлова 3.Х., Хакимьянов М.И., Хазиева Р.Т., 2020 